\title{
Impact of future price increase on ordering policies for deteriorating items under quadratic demand
}

\author{
Nita H. Shah ${ }^{a^{*}}$, Mrudul Y. Jani ${ }^{\mathrm{b}}$ and Urmila Chaudhari ${ }^{\mathrm{b}}$
}

${ }^{a}$ Department of Mathematics, Gujarat University, Ahmedabad-380009, Gujarat, India

${ }^{b}$ Department of Applied Sciences, Faculty of Engineering and Technology, Parul University, Vadodara-391760, Gujarat, India

\begin{tabular}{l}
\hline C H R O N I C L E \\
\hline Article history: \\
Received October 312015 \\
Received in Revised Format \\
December 212015 \\
Accepted December 212015 \\
Available online \\
December 23 2015 \\
\hline Keywords: \\
Inventory \\
Deteriorating items \\
Price increase \\
Quadratic demand
\end{tabular}

\section{Introduction}

Because of the current rises in the prices of oil and raw materials, the prices of commodities have continued to increase at universal level. This is the serious issue for enterprises. In particular, when supervisors make decisions relating to their inventory policy, it is essential for them to consider increases in goods prices. When a supplier announces an impending price increase from effect at a certain time in the future, it is important for each retailer to decide whether to purchase sufficient stock before the price increase, to take advantage of the present lower price. Researchers have taken the declaration of a price increase problem into account and have proposed various analytical models to get more insights into the decisions relating to inventory policy. Naddor (1966) proposed an infinite horizon economic order quantity (EOQ) model where the supplier announces a price increase. Lev and Soyster (1979) established a finite horizon inventory model and determined optimal ordering policies based on known information

* Corresponding author.

E-mail: nitahshah@gmail.com (N. H. Shah)

(C) 2016 Growing Science Ltd. All rights reserved. doi: $10.5267 /$ j.ijiec.2015.12.006 
about an imminent price increase. Later, Goyal (1979) studied Lev and Soyster's (1979) model and proposed an alternative method for determining the optimal policy. Taylor and Bradley (1985) extended Naddor's (1966) model and found the optimal ordering strategies for situations where the price increase does not coincide with the end of an EOQ cycle. Lev and Weiss (1990) subsequently developed a structure of optimal policies and procedures for computing the optimal policy. Goyal et al. (1991) offered a review of a study on inventory policies under one-time-only incentives. Tersine (1996) suggested an economic production quantity (EPQ) model under an announced price increase. Ghosh (2003) and Huang and Kulkarni (2003) presented an infinite-horizon deterministic inventory model under an announced price increase. In contrast to single price change models, a small number of continuous price change models exist within inventory management literature. Erel (1992) and Khouja and Park (2003) considered EOQ models with continuous price changes (price increases or reductions). Recently, Tripathi and Tomar (2015) studied optimal ordering policy for deteriorating items with time-dependent demand in response to temporary price discount linked to order quantity. They considered constant rate of deterioration.

The above inventory models account for the impact of price changes and focus on the determination of the optimal special order quantity for the retailer. A weakness with most of them is that they neglect the deterioration of goods, which is a common phenomenon. It is obvious that certain products, such as medicine, volatile liquids, fruits, and vegetables, will deteriorate when kept in storage for a long period. For such products, losses due to deterioration cannot be ignored when determining the optimal order policy. Inventory problems relating to deteriorating items have been studied extensively in previous research. Ghare and Schrader (1963) first established an EOQ model for an exponentially decaying item for which there is constant demand. Later, Covert and Philip (1973) extended Ghare and Schrader's (1963) model and developed an EOQ model for a variable deterioration rate, by assuming a twoparameter Weibull distribution. Philip (1974) then obtained an inventory model with a three-parameter Weibull distribution deterioration rate. Goyal and Giri (2001) provided an excellent and detailed review of the literature on deteriorating inventory since the early 1990s.Moon et al. (2005) formulated a model to incorporate two extreme physical characteristics of stored items into inventory model ameliorating (value or utility increase with time) and deteriorating. Bakker et al. (2012) have undertaken an up-to-date review of the advances made in the field of inventory control of perishable items (deteriorating inventory) since 2001. Recently, Tayal et al. (2014) has investigated an inventory model for deteriorating items with seasonal products and an option of an alternative market. Freshly, Singh et al.(2015) an economic order quantity model for deteriorating products having stock dependent demand with trade credit period and preservation technology. There is also a large body of literature on deteriorating inventory. These cover issues such as the type of demand (viz., Begum et al. (2012), Deng, et al. (2007), Khanra et al. (2010), Mishra and Shah (2008); Skouri and Konstantaras (2009); accounting for the time-value of money (viz., Wee and Law (1999, 2001); allowing shortages and backordering viz. Shah (1998), Sharma (2006), Yang (2011); considering multiple items viz. Sharma (2007a, 2007b, 2009b); the EPQ model viz. Min et al. (2012), Sharma (2008a, 2008b, 2009c); and the two-warehouse problem viz. Pakkala and Achary (1992), Sarma (1987), Yang, (2006).

Most of the above research reveals that retailers are inclined to adopt a special order, with the special order quantity involved being unlimited, when suppliers announce a price increase. In practice, to avoid the retailer hoarding goods for later sale at a higher selling price, the supplier is willing to offer a limited quantity at the current price prior to the price increase. Therefore, the number of goods the retailer can order is also limited. Thus, in order to discuss the above economic topics, this study examines the possible effects of a price increase on a retailer's replenishment policies. The contribution of this article, relative to previous studies, is that we explore inventory decisions and the three issues of the traditional EOQ model simultaneously. These comprise of the following: (1) the retailer expects the price increase at a certain time in the future (as announced by the supplier) and decides whether to place a special order; (2) the goods deteriorate at a constant rate; and (3) the demand is quadratic in nature. Additionally, because the time for placing the special order may or may not coincide with the replenishment time, we consider 
two cases: (I) when the special order time matches with the retailer's replenishment time and (II) when the special order time occurs during the retailer's sales period. In Case I, the retailer's optimal order policy is to decide whether to place a larger order which is always larger than regular EOQ. In Case II, the retailer's optimal order policy is to decide whether to place an additional order which is not necessary larger than regular EOQ. The purpose of this study is to determine the retailer's optimal order policies in response to a price increase by maximising the total cost saving between special and regular orders during the depletion time of the special order quantity. We provide two numerical examples to illustrate the theories in practical use, and we conduct a sensitivity analysis of the optimal solution by examining the main parameters.

\section{Notations and assumptions}

We shall use following notations and assumptions to build up the mathematical model of the problem under consideration.

\subsection{Notations}

$\begin{array}{ll}A & \text { Ordering cost per order } \\ C & \text { Purchase cost per unit } \\ i & \text { Inventory holding cost (excluding interest charges) per unit per unit time } \\ \theta & \text { Constant deterioration rate, } 0 \leq \theta<1 \text { and is a constant } \\ k & \text { Price increase per unit } \\ R(t) & \text { Quadratic demand } \\ T & \text { Length of replenishment cycle time before price increase } \\ I(t) & \text { Inventory level at any instant of time } t \text { before the price increase, } 0 \leq t \leq T \\ Q & \text { Order quantity (units/order) before the price increase } \\ Q_{I} & \text { Order quantity (units/order) after the price increase } \\ T_{I} & \text { Length of replenishment cycle time after price increase } \\ Q_{s} & \text { Special order quantity before the price increase (decision variable) } \\ T_{s} & \text { Depletion time for the special order quantity } Q_{s} \text { (decision variable) } \\ q & \text { Residual inventory level when the special order is placed } \\ t_{q} & \text { The length of time until the special order is placed during the retailer's regular replenishment } \\ T_{q} & \text { period } \\ I_{s}(t) & \text { Depletion time for the inventory quantity } Q_{s}+q \\ I_{q}(t) & \text { Inventory level at any instant of time } t \text { when the special order is adopted } 0 \leq t \leq T_{s} \\ T C(T) & \text { Inventory level at any instant of time } t \text { during the time interval }\left[0, T_{q}\right] \\ T C\left(T_{I}\right) & \text { Total cost per unit time during the replenishment period } T \\ g_{i}\left(T_{s}\right) & \text { Total cost per unit time during the replenishment period } T_{I} \\ 2.2 A s s u m p t i o n s & \text { for } i, i=1,2\end{array}$

1. The system under review deals with single item

2. The demand rate is $R(t)=a\left(1+b t-c t^{2}\right)$, where $a>0$ denotes the scale demand, $b$ and $c$ denotes linear and quadratic demand rates. The functional form of demand rate suggests that demand increases linearly and decreases quadratically. This demand is justified for electronic gadgets, fashion goods, medicines during epidemics. 
3. To reflect the increasing price of raw materials, the supplier announces that the unit price of an item will increase by a given amount $k$, at a certain future date.

4. The retailer has only one opportunity to replenish its stock at the present price before the price increases

5. The replenishment rate is infinite and the lead-time is zero.

6. Shortages are not allowed

7. There is no replacement or repair of deteriorated units during the period under consideration.

\section{Mathematical Model}

This article focuses on the possible effects of price increase on a retailer's replenishment strategy, in which, Depletion of the inventory occurs due to the combined effects of demand and physical deterioration. Thus, the change in inventory level before the price increase is described by following differential equation:

$$
\frac{d I(t)}{d t}=-R(t)-\theta(t) I(t), \quad 0<t<T
$$

given the boundary condition $I(T)=0$, the solution of Eq. (1) is represented by

$$
I(t)=\frac{a\left(\theta^{2}-\theta b-2 c+\theta^{2} T b+2 \theta T c-c T^{2} \theta^{2}\right) e^{-\theta t+\theta T}}{\theta^{3}}-\frac{a\left(\theta^{2}-\theta b-2 c+\theta^{2} t b+2 \theta t c-c t^{2} \theta^{2}\right)}{\theta^{3}}, 0 \leq t \leq T
$$

Hence, the order quantity is given by

$$
Q=I(0)=\frac{a\left(\theta^{2}-\theta b-2 c+\theta^{2} T b+2 \theta T c-c T^{2} \theta^{2}\right) e^{\theta T}}{\theta^{3}}-\frac{a\left(\theta^{2}-\theta b-2 c\right)}{\theta^{3}}
$$

Earlier to the price increase, the purchasing $\operatorname{cost} C$ follows the fixed economic order strategy with a unit purchasing cost, $C$, the total cost during the replenishment period $T$ being the sum of the ordering cost, purchasing cost and holding cost, i.e.,

$$
A+C Q+C i \int_{0}^{T} I(t) d t
$$

Therefore, the total cost per unit time is

$$
T C(T)=\frac{1}{T}\left(A+C Q+C i \int_{0}^{T} I(t) d t\right)
$$

It can easily be shown that $T C(T)$ is a convex function of $T$.Thus, there is a unique value for $T$ (say $T_{0}$ ) that minimises $T C(T)$. The value of $T_{0}$ can be obtained by solving the equation $\frac{d T C(T)}{d T}=0$.

Once the optimal length of replenishment cycle time, $T_{0}$, is obtained, the optimal order quantity, $Q_{0}$ , is obtained as follows:

$$
Q_{0}=\frac{a\left(\theta^{2}-\theta b-2 c+\theta^{2} T_{0} b+2 \theta T_{0} c-c T_{0}^{2} \theta^{2}\right) e^{\theta T_{0}}}{\theta^{3}}-\frac{a\left(\theta^{2}-\theta b-2 c\right)}{\theta^{3}}
$$

Next, when unit purchasing cost increases from $C$ to $(C+k)$, the total cost per unit time becomes 


$$
T C\left(T_{I}\right)=\frac{1}{T_{I}}\left(A+(C+k) Q_{I}+(C+k) i \int_{0}^{T_{I}} I(t) d t\right),
$$

where, $Q_{I}=\frac{a\left(\theta^{2}-\theta b-2 c+\theta^{2} T_{I} b+2 \theta T_{I} c-c T_{I}^{2} \theta^{2}\right) e^{\theta T_{I}}}{\theta^{3}}-\frac{a\left(\theta^{2}-\theta b-2 c\right)}{\theta^{3}}$

Similarly, there is a unique value for $T_{I}$ (say $\left.T_{I 0}\right)$ that minimises $T C\left(T_{I}\right)$. The value of $T_{I 0}$ can be obtained by solving the equation $\frac{d T C\left(T_{I}\right)}{d T_{I}}=0$. The corresponding optimal order quantity, $Q_{I 0}$, is

$$
Q_{I 0}=\frac{a\left(\theta^{2}-\theta b-2 c+\theta^{2} T_{I 0} b+2 \theta T_{I 0} c-c T_{I 0}^{2} \theta^{2}\right) e^{\theta T_{I 0}}}{\theta^{3}}-\frac{a\left(\theta^{2}-\theta b-2 c\right)}{\theta^{3}}
$$

Consequently, when a supplier announces a price increase that is effective from a particular future period, the retailer may place a special order to take benefit of the current lower price, $C$, before the price increases. On the other hand, the retailer may ignore this notice and place a regular order. The purpose of this study is to determine the optimal special order quantity by maximising the total cost saving between special and regular orders during the depletion time of the special order quantity. As specified previously, two specific situations arise, which we discuss in this article: (I) when the special order time matches with the retailer's replenishment time and (II) when the special order time take place during the retailer's sales period. Next, we will formulate the resultant total relevant inventory cost saving function for these two cases.

\subsection{Case I: the special order time matches with the retailer's replenishment time}

In this case, if the retailer decides to adopt a special order and orders $Q_{s}$ units, then the inventory level at time $t$ is

$$
I_{s}(t)=\frac{a\left(\theta^{2}-\theta b-2 c+\theta^{2} T_{s} b+2 \theta T_{s} c-c T_{s}^{2} \theta^{2}\right) e^{\left(-\theta t+\theta T_{s}\right)}}{\theta^{3}}-\frac{a\left(\theta^{2}-\theta b-2 c+\theta^{2} t b+2 \theta t c-c t^{2} \theta^{2}\right)}{\theta^{3}}, 0 \leq t \leq T_{s}
$$

The special order quantity at the original unit purchasing price, $C$, is

$$
Q_{s}=I_{s}(0)=\frac{a\left(\theta^{2}-\theta b-2 c+\theta^{2} T_{s} b+2 \theta T_{s} c-c T_{s}^{2} \theta^{2}\right) e^{\theta T_{s}}}{\theta^{3}}-\frac{a\left(\theta^{2}-\theta b-2 c\right)}{\theta^{3}}
$$

The total cost of the special order during the time interval $\left[0, T_{s}\right]$ (denoted by $\operatorname{TC} S_{1}\left(T_{s}\right)$ ) consist of ordering cost, purchasing cost and holding cost, and is represented by

$$
T C S_{1}\left(T_{s}\right)=A+C Q_{s}+C i \int_{0}^{T_{s}} I(t) d t
$$

If the retailer places its regular order, then the total cost of a regular order during the time interval $\left[0, T_{s}\right]$ will be divided into two periods (see fig.(1)). In the first period, the retailer orders $Q_{0}$ units at the unit purchasing price $C$. The corresponding total cost is similar to Eq. (4), and is described by

$$
A+C Q_{0}+C i \int_{0}^{T_{0}} I(t) d t
$$




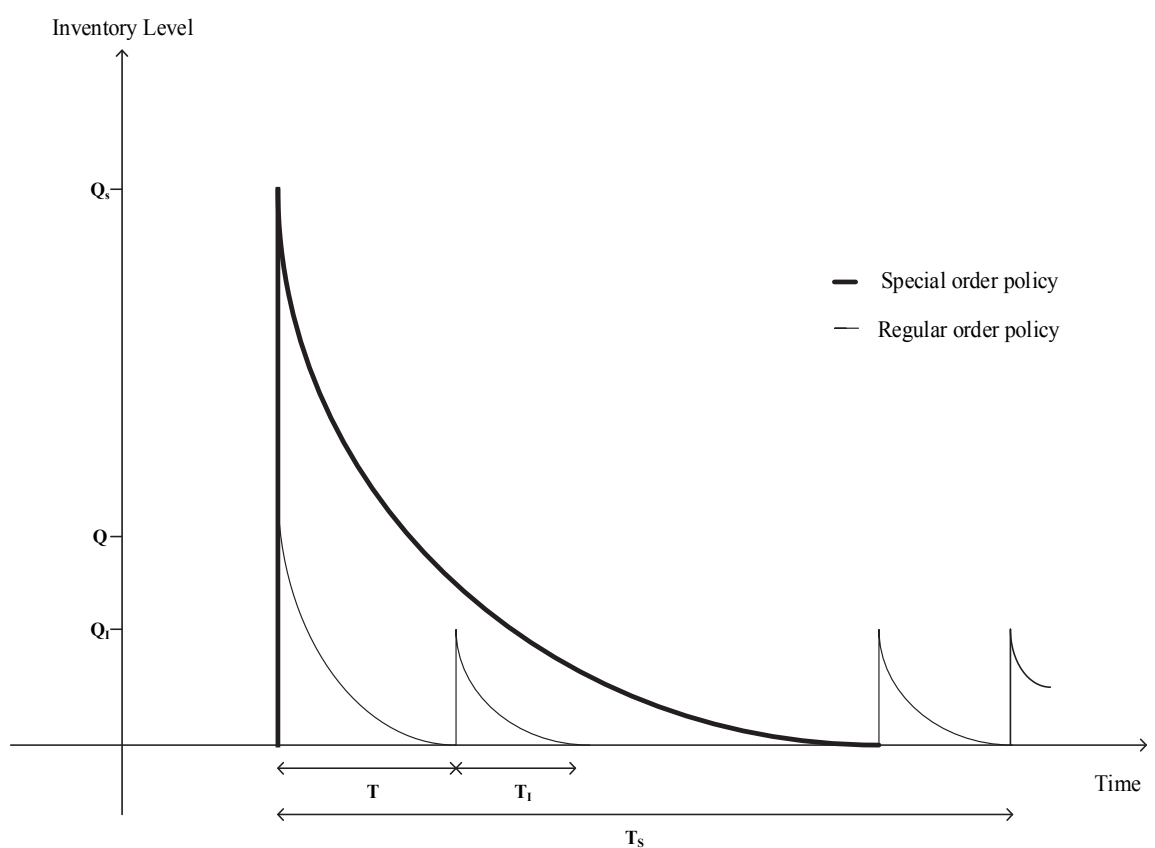

Fig. 1. Special vs. regular order policies when the special order time coincides with the retailer's replenishment time

As to the rest period, the retailer follows regular EOQ policy for the unit purchasing price $(C+k)$. Hence, the total cost during the rest period is given by

$$
\frac{T_{s}-T_{0}}{T_{I 0}}\left(A+(C+k) Q_{I 0}+(C+k) i \int_{0}^{T_{I 0}} I(t) d t\right)
$$

Subsequently, the total cost of a regular order during the time interval $\left[0, T_{s}\right]$ (denoted by $T C N_{1}\left(T_{s}\right)$ ) is

$$
T C N_{1}\left(T_{s}\right)=A+C Q_{0}+C i \int_{0}^{T_{0}} I(t) d t+\frac{T_{s}-T_{0}}{T_{I 0}}\left(A+(C+k) Q_{I 0}+(C+k) i \int_{0}^{T_{I 0}} I(t) d t\right)
$$

Compering Eq. (11) with Eq.(14), the total cost saving when the special order coincides with the retailer's replenishment time (i.e., Case I) can be expressed as follows:

$$
g_{1}(T s)=T C N_{1}(T s)-T C S_{1}(T s)
$$

Simply it can be shown that $g_{1}\left(T_{s}\right)$ is a concave function of $T_{s}$. Hence, there is a unique value for $T_{s}$ (say $\left.T_{s 1}\right)$ that maximises $g_{1}\left(T_{s}\right)$. The value of $T_{s 1}$ can be obtained by solving the equation $\frac{d g_{1}\left(T_{s}\right)}{d T_{s}}=0$

\subsection{Case II: the special order time take place during the retailer's sales period}

Sometimes, the time of the price increase arises during the retailer's sales period. In this state, if the retailer decides to place a special order of quantity $Q_{s}$ at the present price $C$, the inventory level will 
increase instantaneously from $q$ to $Q_{s}+q$ when the special order quantity is supplied (see Fig.(2)). Conversely, if the retailer pays no attention to the notification about the price increase, that retailer will not place any orders until the next replenishment. We will formulate the total cost functions for the special and regular order policies and then compare the two.

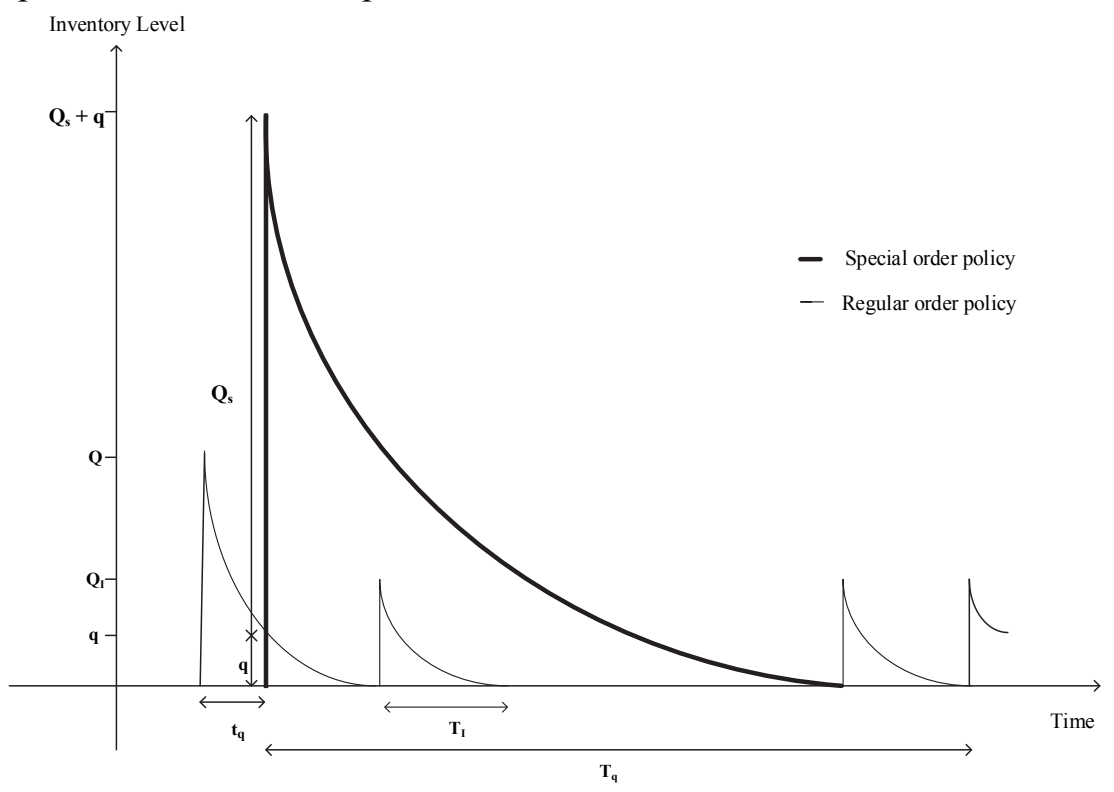

Fig. 2. Special vs. regular order policies when the special order time occurs during the retailer's sales

$$
\text { period }
$$

When a special order is placed, the total cost during the time interval $\left[0, T_{q}\right]$ consists of the ordering cost, purchasing cost and holding cost, which is expressed as follows.

As the special order quantity attains, the maximum inventory is given by

$$
\begin{aligned}
& Q_{s}+q=\frac{a\left(\theta^{2}-\theta b-2 c+\theta^{2} T_{s} b+2 \theta T_{s} c-c T_{s}^{2} \theta^{2}\right) e^{\theta T_{s}}}{\theta^{3}}-\frac{a\left(\theta^{2}-\theta b-2 c\right)}{\theta^{3}} \\
& +\frac{a\left(\theta^{2}-\theta b-2 c+\theta^{2}\left(T_{0}-t_{q}\right) b+2 \theta\left(T_{0}-t_{q}\right) c-c\left(T_{0}-t_{q}\right)^{2} \theta^{2}\right) e^{\theta\left(T_{0}-t_{q}\right)}}{\theta^{3}}-\frac{a\left(\theta^{2}-\theta b-2 c\right)}{\theta^{3}}
\end{aligned}
$$

Moreover, the inventory level at time $t$ during the time interval $\left[0, T_{q}\right]$ can be obtained by

$$
I_{q}(t)=\frac{a\left(\theta^{2}-\theta b-2 c+\theta^{2} T_{q} b+2 \theta T_{q} c-c T_{q}^{2} \theta^{2}\right) e^{\left(-\theta t+\theta T_{q}\right)}}{\theta^{3}}-\frac{a\left(\theta^{2}-\theta b-2 c+\theta^{2} t b+2 \theta t c-c t^{2} \theta^{2}\right)}{\theta^{3}}, 0 \leq t \leq T_{q}
$$

Now, because of $I_{q}(0)=Q_{s}+q$, from Eq. (16) and Eq. (17), we have

$$
\begin{aligned}
& \frac{a\left(\theta^{2}-\theta b-2 c+\theta^{2} T_{s} b+2 \theta T_{s} c-c T_{s}^{2} \theta^{2}\right) e^{\theta T_{s}}}{\theta^{3}}-\frac{a\left(\theta^{2}-\theta b-2 c\right)}{\theta^{3}} \\
& +\frac{a\left(\theta^{2}-\theta b-2 c+\theta^{2}\left(T_{0}-t_{q}\right) b+2 \theta\left(T_{0}-t_{q}\right) c-c\left(T_{0}-t_{q}\right)^{2} \theta^{2}\right) e^{\theta\left(T_{0}-t_{q}\right)}}{\theta^{3}}-\frac{a\left(\theta^{2}-\theta b-2 c\right)}{\theta^{3}} \\
& =\frac{a\left(\theta^{2}-\theta b-2 c+\theta^{2} T_{q} b+2 \theta T_{q} c-c T_{q}^{2} \theta^{2}\right) e^{\left(-\theta t+\theta T_{q}\right)}}{\theta^{3}}-\frac{a\left(\theta^{2}-\theta b-2 c\right)}{\theta^{3}}
\end{aligned}
$$


Now, avoiding higher order terms of $\theta$, we can find $T_{q}$ as follows

$$
T q=-\frac{1}{\theta^{3}}\left(\begin{array}{l}
-e^{\theta T_{s}} \theta^{2}+e^{\theta T_{s}} \theta b+2 e^{\theta T_{s}} c-e^{\theta T_{s}} \theta^{2} T_{s} b \\
-2 e^{\theta T_{s}} \theta T_{s} c+e^{\theta T_{s}} \theta^{2} T_{s}^{2} c+2 \theta^{2}-2 \theta b \\
-4 c-e^{\theta\left(T-t_{q}\right)} \theta^{2}+e^{\theta\left(T-t_{q}\right)} \theta b+2 e^{\theta\left(T-t_{q}\right)} c \\
-e^{\theta\left(T-t_{q}\right)} \theta^{2} T b+e^{\theta\left(T-t_{q}\right)} \theta^{2} b t_{q}-2 e^{\theta\left(T-t_{q}\right)} \theta T c \\
+2 e^{\theta\left(T-t_{q}\right)} \theta c t_{q}+e^{\theta\left(T-t_{q}\right)} c T^{2} \theta^{2}-2 e^{\theta\left(T-t_{q}\right)} \theta^{2} c T t_{q}+e^{\theta\left(T-t_{q}\right)} \theta^{2} c t_{q}^{2}
\end{array}\right)
$$

Thus, total cost of the special order during the time interval $\left[0, T_{q}\right]\left(\right.$ denoted by $\left.\operatorname{TCS} S_{2}\left(T_{s}\right)\right)$ can be described as follows:

$$
T C S_{2}\left(T_{s}\right)=A+C Q_{s}+C i \int_{0}^{T_{q}} I_{q}(t) d t
$$

In contrast, if the retailer ignores announcement of the price increase and places its regular order, the total cost during the time interval $\left[0, T_{q}\right]$ will also be divided into two phases. In the first period, the retailer only has the cost during the depletion time of residual $q, T_{0}-t_{q}$. We use the average cost analysis approach, which gives us the following:

$$
\frac{T_{0}-t_{q}}{T_{0}}\left(A+C Q_{0}+C i \int_{0}^{T_{0}} I(t) d t\right)
$$

Afterward, the retailer places the regular order with the unit purchase $\operatorname{cost}(C+k)$ during the rest period. To obtain the total cost in this period, we use the average cost analysis method, which is given by

$$
\frac{T_{q}-\left(T_{0}-t_{q}\right)}{T_{I 0}}\left(A+(C+k) Q_{I 0}+(C+k) i \int_{0}^{T_{I 0}} I(t) d t\right)
$$

As a result, when the retailer ignores the notification and places its regular order during the time interval $\left[0, T_{q}\right]$, the total cost (denoted by $T C N_{2}\left(T_{s}\right)$ ) is

$$
\begin{aligned}
T C N_{2}\left(T_{s}\right) & =\frac{T_{0}-t_{q}}{T_{0}}\left(A+C Q_{0}+C i \int_{0}^{T_{0}} I(t) d t\right) \\
& +\frac{T_{q}-\left(T_{0}-t_{q}\right)}{T_{I 0}}\left(A+(C+k) Q_{I 0}+(C+k) i \int_{0}^{T_{I 0}} I(t) d t\right)
\end{aligned}
$$

Hence, the total cost saving when the special order time occurs during the retailer's sales period can be formulated as follows:

$$
g_{2}(T s)=T C N_{2}(T s)-T C S_{2}(T s)
$$

Simply it can be shown that $g_{2}\left(T_{s}\right)$ is a concave function of $T_{s}$. Hence, there is a unique value for $T_{s}$ (say $\left.T_{s 2}\right)$ that maximises $g_{2}\left(T_{s}\right)$. The value of $T_{s 2}$ can be obtained by solving the equation $\frac{d g_{2}\left(T_{s}\right)}{d T_{s}}=0$. 
Remark: Note that it is worth placing a special order only when the total cost saving is positive in the above two cases. Otherwise, the retailer will ignore the opportunity to place the special order.

\section{Numerical Examples}

The developed mathematical model is illustrated in the following numerical examples. The retailer's total cost per unit time is optimized using Maple XVI is given in Table 1.

Table 1

Numerical data

\begin{tabular}{ccc}
\hline \multirow{2}{*}{ Parameters } & \multicolumn{3}{c}{ Examples } \\
\cline { 2 - 3 } & 1 & 2 \\
\hline$a$ & 100 & 100 \\
$b$ & 0.2 & 0.2 \\
$c$ & 0.3 & 0.3 \\
$A$ & 50 & 50 \\
$\theta$ & 0.2 & 0.2 \\
$i$ & 0.2 & 0.2 \\
$C$ & 20 & 20 \\
$k$ & 4 & 4 \\
\hline$T_{s}$ (in years) & \multicolumn{2}{c}{ Optimal Solution } \\
\hline$Q_{s}$ (units) & 0.698 & 2.189 \\
$g_{i}\left(T_{s}\right) i=1,2$ (in \$) & 76.59 & 192.97 \\
\hline
\end{tabular}

The concavity of the gain functions are shown in Fig. 3 and 4. (Appendix A)

\section{Sensitivity analysis}

Now, for data of Example 1, we study the effects of various inventory parameters on total cost savings $g_{1}\left(T_{s}\right)$, decision variables order quantity $Q_{s}$ and time period $T_{s}$ by changing them as $-20 \%,-10 \%$, $10 \%$ and $20 \%$.

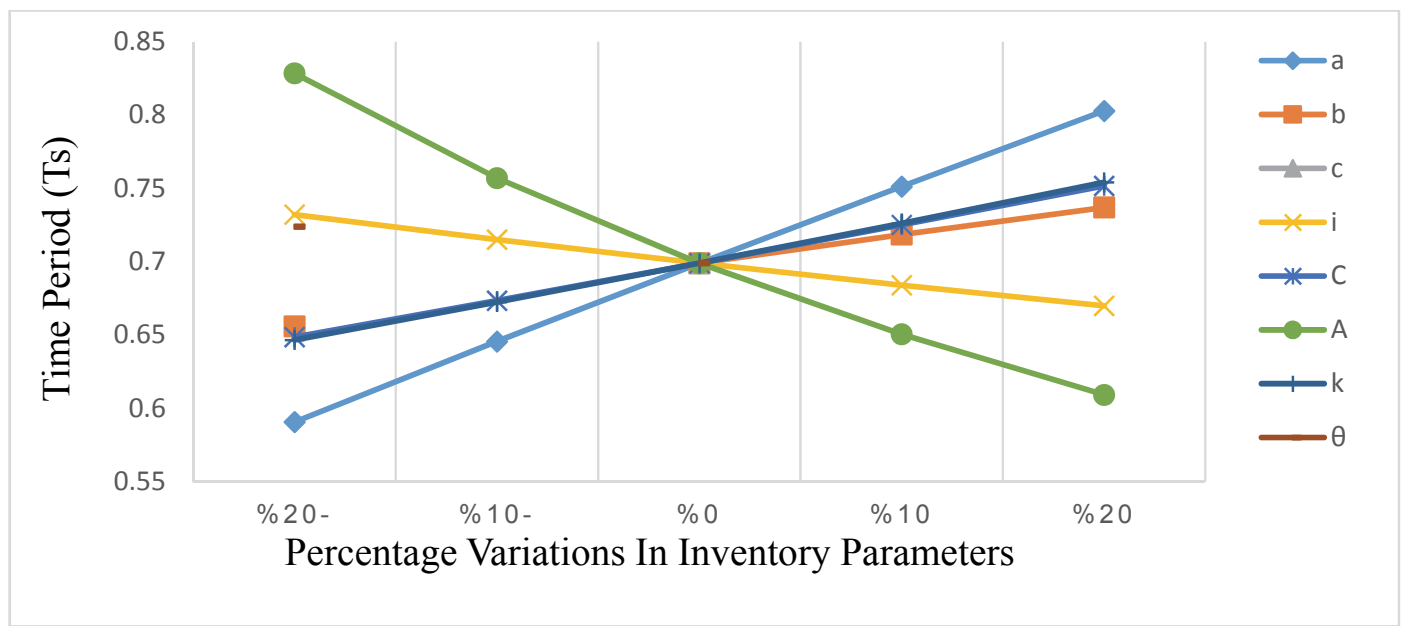

Fig. 5 Variations in time period $T_{s}$ w. r. t. inventory parameters 
From Fig. 5, it is noticed that unit purchase price $(C)$ and unit price increase $(k)$ has huge positive impact on time period. Whereas, scaled demand $(a)$ and linear rate of change of demand $(b)$ increases time period slowly. If holding cost $(i)$ increases then clearly time period decreases. Ordering $\operatorname{cost}(A)$ has large negative effect on time period.

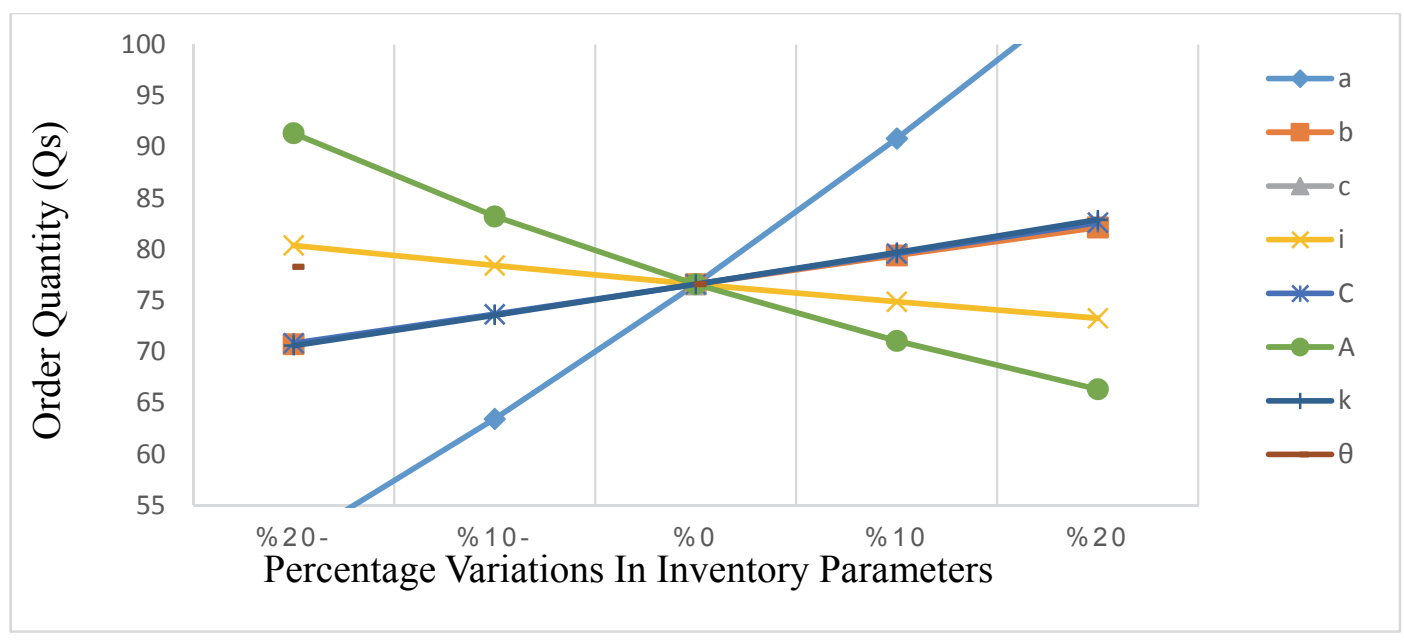

Fig. 6. Variations in order quantity $Q_{s}$ w. r. t. inventory parameters

From Fig. 6, it is observed that scaled demand $(a)$ has huge positive impact on order quantity. Whereas, unit purchase price $(C)$, unit price increase $(k)$ and linear rate of change of demand $(b)$ increases order quantity slowly. On the other hand, if holding cost $(i)$ increases then clearly order quantity decreases. Ordering $\operatorname{cost}(A)$ has big negative effect on order quantity.

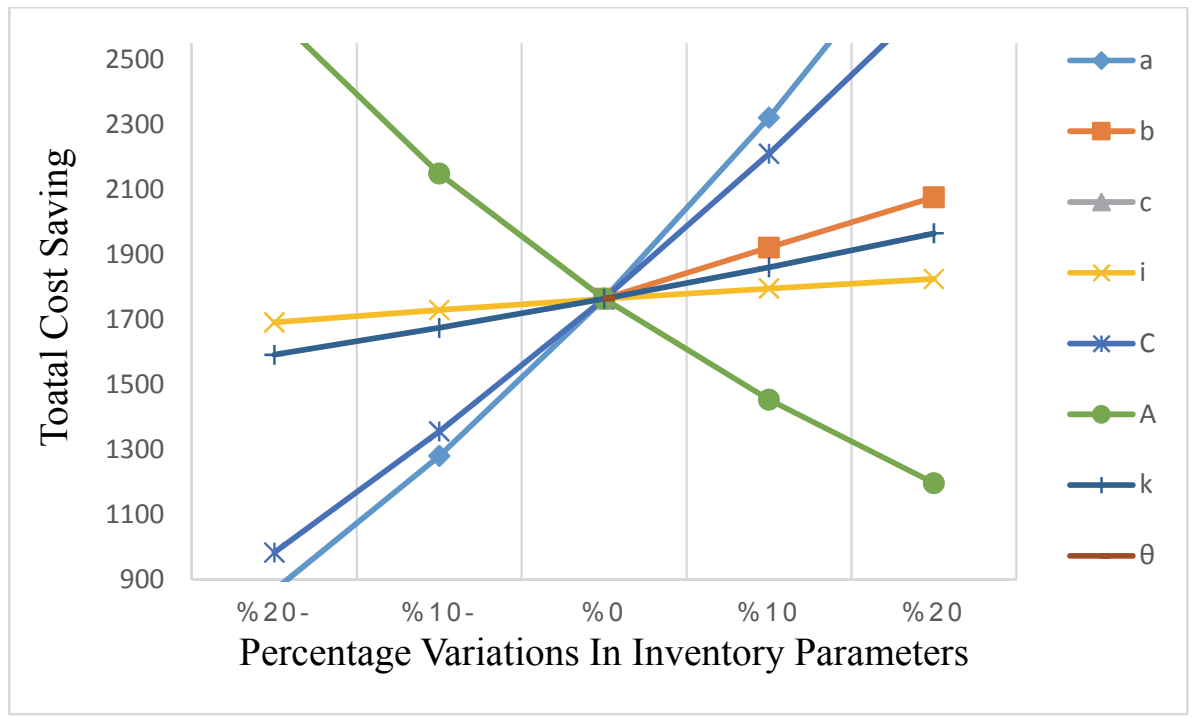

Fig. 7. Variations in total cost saving $g_{1}\left(T_{s}\right)$ w. r. t. inventory parameters

From Fig. 7, it is observed that scaled demand $(a)$ and unit purchase price $(C)$ has huge positive impact on total cost saving. Holding $\operatorname{cost}(i)$, linear rate of change of demand $(b)$ and unit price increase $(k)$ increases total cost saving gradually. Whereas, ordering $\operatorname{cost}(A)$ has large negative effect on total cost 
saving. Now, for Example 2, we study the effects of various inventory parameters on total cost savings $g_{2}\left(T_{s}\right)$, decision variables order quantity $Q_{s}$ and time period $T_{s}$ by changing them as $-20 \%,-10 \%$, $10 \%$ and $20 \%$.

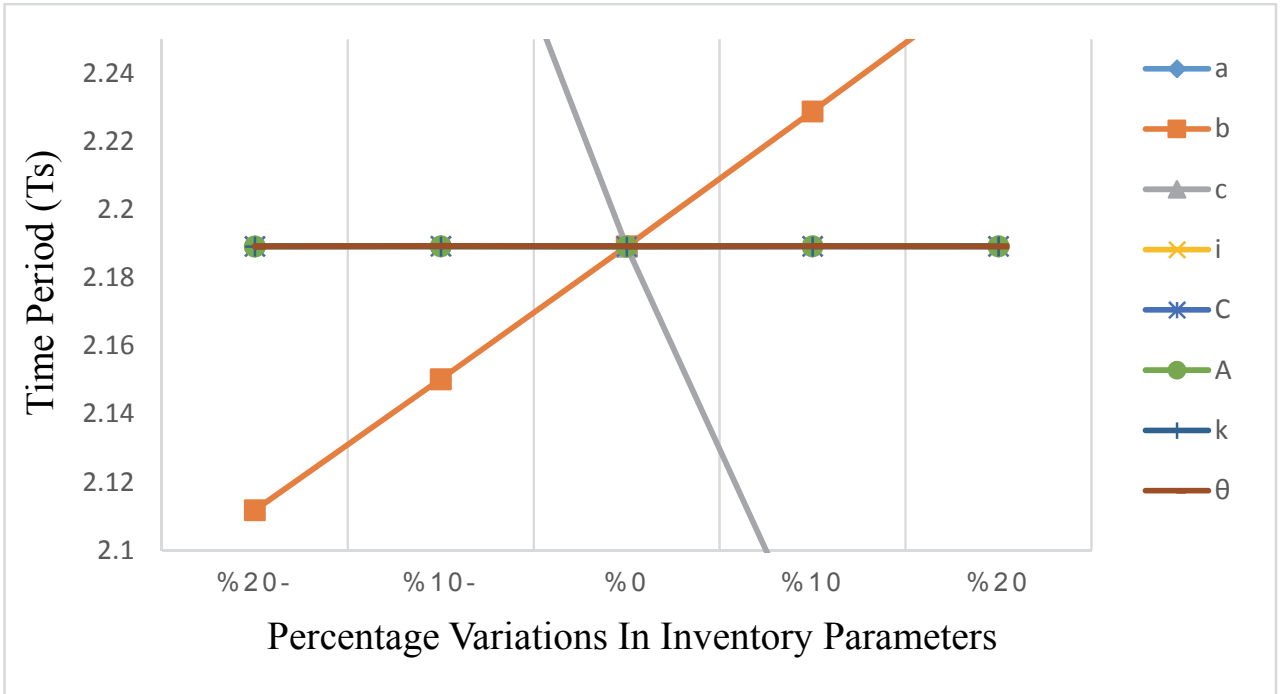

Fig. 8. Variations in time period $T_{s}$ w. r. t. inventory parameters

From Fig. 8, it is observed that unit price increase $(k)$ and linear rate of change of demand $(b)$ has great positive impact on time period, whereas, quadratic rate of change of demand $(c)$ has huge negative effect on time period.

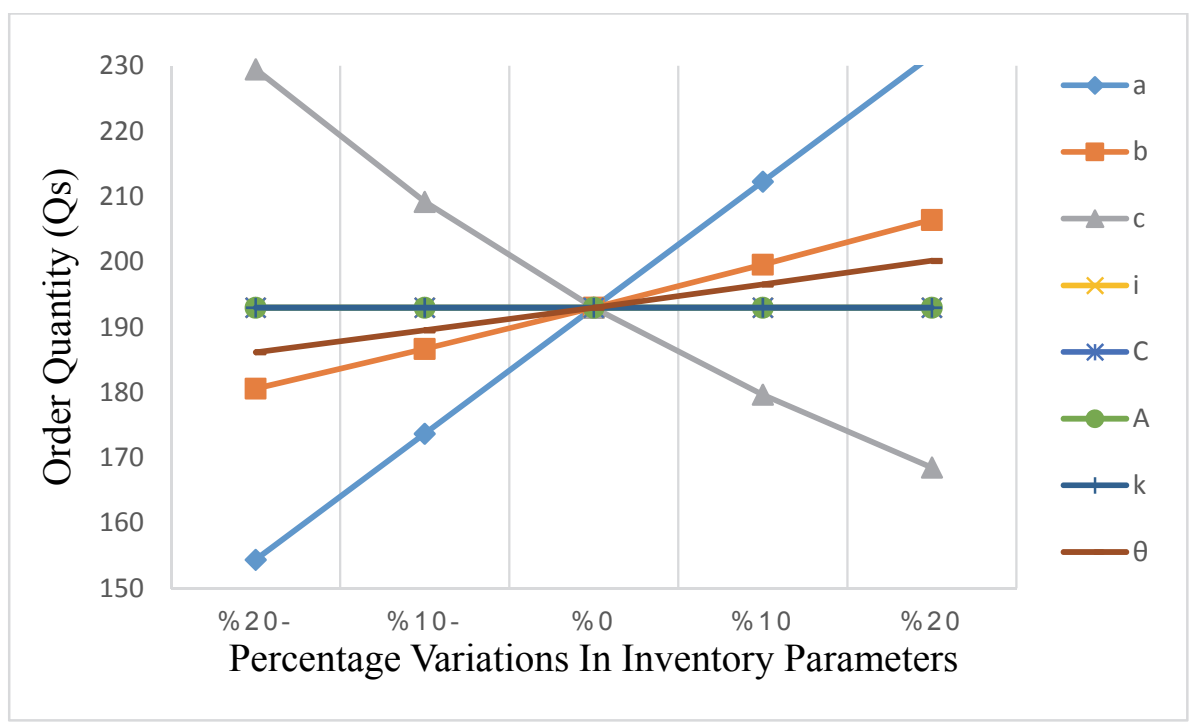

Fig. 9. Variations in order quantity $Q_{s}$ w. r. t. inventory parameters

From Fig. 9, it is observed that scaled demand $(a)$ has huge positive impact on order quantity. Linear rate of change of demand $(b)$ and deterioration rate $(\theta)$ increases order quantity slowly. However, unit 
price increase $(k)$ decreases order quantity gently. Quadratic rate of change of demand $(c)$ has enormous negative effect on order quantity.

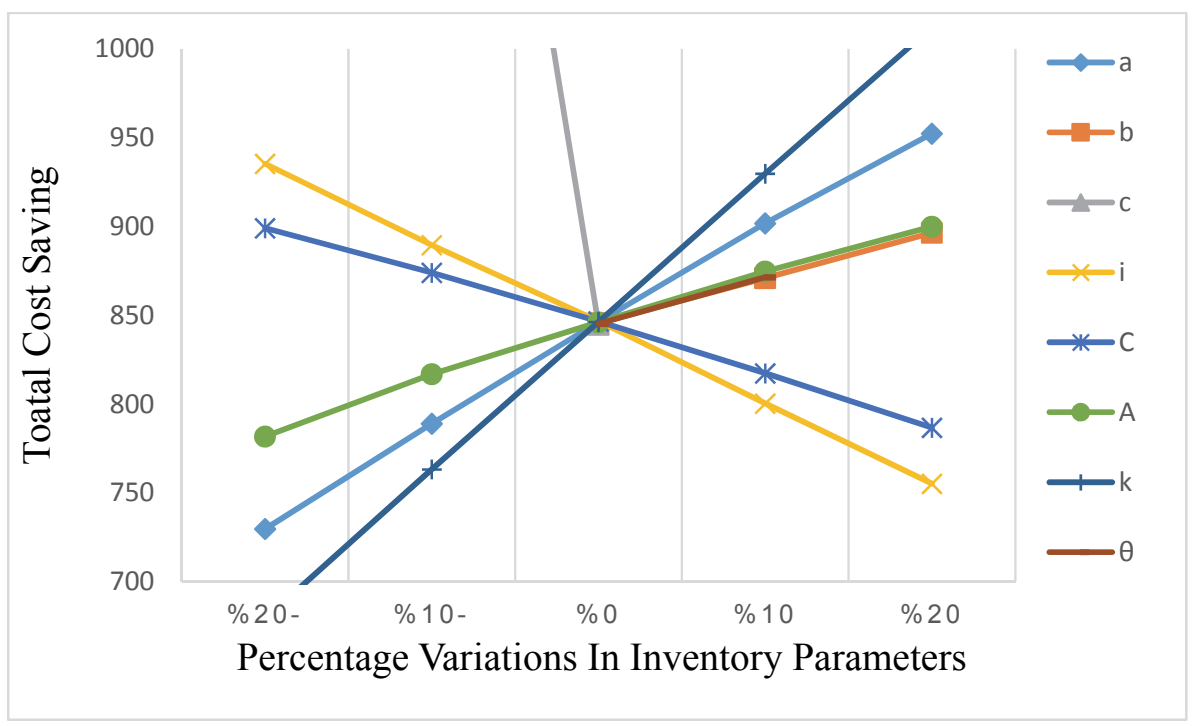

Fig. 10. Variations in total cost saving $g_{2}\left(T_{s}\right)$ w. r. t. inventory parameters

From Fig. 10, it is observed that scaled demand $(a)$ unit price increase $(k)$ has huge positive impact on total cost saving. Ordering $\operatorname{cost}(A)$ increases total cost saving slowly. On the other unit purchase price $(C)$ decreases total cost saving gradually. Holding $\cos t(i)$ has great negative effect on total cost saving.

\section{Conclusion}

The article analyzes the effect of a price increase announcement by a supplier on retailers' decision policies when demand is decreasing quadratically and items in retailers' inventory deteriorate at a constant rate. The total cost savings between special and regular ordering is maximized. Results are validated with numerical examples. It is advocated that placing an order at a lower price benefits the retailer. Also, increase in deterioration rate and holding cost decreases total cost savings. When retailers' regular replenishment time coincides with that of the special order time, savings can be increased by having higher residual inventory.

\section{Acknowledgement}

The authors will like to thank reviewer for constructive feedback. The first author is thankful to DSTFIST File \# MSI-097 for support to carry out this research.

\section{References}

Bakker, M., Riezebos, J., \& Teunter, R.H. (2012). Review of inventory systems with deterioration since 2001. European Journal of Operational Research, 221(2), 275-284.

Begum, R., Sahoo, R.R., \& Sahu, S.K. (2012). A replenishment policy for items with price-dependent demand, time proportional deterioration and no shortages. International Journal of Systems Science, 43(5), 903-910.

Covert, R. P., \& Philip, G.C. (1973). An EOQ model for items with Weibull distribution deterioration. AIIE transactions, 5(4), 323-326. 
Deng, P.S., Lin, R.H., \& Chu, P.A. (2007). A note on the inventory models for deteriorating items with ramp type demand rate. European Journal of Operational Research, 178(1), 112-120.

Erel, E. (1992). The effect of continuous price change in the EOQ. Omega, 20(4), 523-527.

Ghare, P.M., \& Schrader, G.H. (1963). A model for exponentially decaying inventory system. Journal of Industrial Engineering, 163, 238-243.

Ghosh, A.K. (2003). On some inventory models involving shortages under an announced price increase. International Journal of Systems Science, 34(2), 129-137.

Goyal, S.K. (1979). A note on the paper: An inventory model with finite horizon and price changes. Journal of the Operational Research Society, 30, 839-842.

Goyal, S.K., \& Giri, B.C. (2001). Recent trends in modeling of deteriorating inventory. European Journal of Operational Research, 134(1), 1-6.

Goyal, S.K., Srinivasan, G.F., \& Arcelus, F. (1991). One time only incentives and inventory policies. European Journal of Operational Research, 54(1), 1-6.

Huang, W., \& Kulkarni, V.G. (2003). Optimal EOQ for announced price increases in infinite horizon. Operations Research, 51(2), 336-339.

Khanra, S., Sana, S.S., \& Chaudhuri, K. (2010). An EOQ model for perishable item with stock and price dependent demand rate. International Journal of Mathematics in Operational Research, 2(3), 320 335.

Khouja, M., \& Park, S. (2003). Optimal lot sizing under continuous price decrease. Omega, 31(6), 539545.

Lev, B., \& Soyster, A.L. (1979). An inventory model with finite horizon and price changes. Journal of the Operational Research Society, 30(1), 43-53.

Lev, B. and Weiss, H.J. (1990). Inventory models with cost changes. Operations Research, 38(1), 53-63.

Min, J., Zhou, Y.W., Liu, G.Q., \& Wang, S.D. (2012). An EPQ model for deteriorating items with inventory-level-dependent demand and permissible delay in payments. International Journal of Systems Science, 43(6), 1039-1053.

Mishra, P., \& Shah, N.H. (2008). Inventory management of time dependent deteriorating items with salvage value. Applied Mathematical Sciences, 2(16), 793-798.

Moon, I., Giri, B.C., \& Ko, B. (2005). Economic order quantity models for ameliorating/deteriorating items under inflation and time discounting. European Journal of Operational Research, 162(3), 773785.

Naddor, E. (1966). Inventory systems. New York, NY: Wiley.

Orougi, S. (2015). Recent advances in enterprise resource planning.Accounting, 1(1), 37-42.

Pakkala, T.P.M., \& Achary, K.K. (1992). Deterministic inventory model for deteriorating items with two warehouses and finite replenishment rate. European Journal of Operational Research, 57(1), 71-76.

Philip, G.C. (1974). A generalized EOQ model for items with Weibull distribution. AIIE Transactions, 6(2), 159-162.

Sarma, K.V.S. (1987). Deterministic order level inventory model for deteriorating items with two storage facilities. European Journal of Operational Research, 29(1), 70-73.

Shah, N.H. (1998). A discrete-time probabilistic inventory model for deteriorating items under a known price increase. International Journal of Systems Science, 29(8), 823-827.

Sharma, S. (2006). Incorporating fractional backordering in the multi-product manufacturing situation with shelf lives. Journal of Engineering Manufacture, 220(7), 1151-1156.

Sharma, S. (2007a). A procedure to optimize the constrained multiple-item production system. Journal of Engineering Manufacture, 221(3), 467-476.

Sharma, S. (2007b). A procedure for benchmarking in multiproduct manufacturing. Journal of Engineering Manufacture, 221(3), 541-546.

Sharma, S. (2008a). On the flexibility of demand and production rate. European Journal of Operational Research, 190(2), 557-561.

Sharma, S. (2008b). Effects of an increase in manufacturing rate in the context of cyclic production. International Journal of Advanced Manufacturing Technology, 39(7-8), 821-827. 
Sharma, S. (2009b). Revisiting the shelf life constrained multiproduct manufacturing problem. European Journal of Operational Research, 193(1), 129-139.

Sharma, S. (2009c). A composite model in the context of a production-inventory system. Optimization Letters, 3(2), 239-251.

Singh, S.R., Khurana, D., \& Tayal, S. (2015). An economic order quantity model for deteriorating products having stock dependent demand with trade credit period and preservation technology. Uncertain Supply Chain Management, 4(1), 29-42.

Skouri, K., \& Konstantaras, I. (2009). Order level inventory models for deteriorating seasonable/fashionable products with time dependent demand and shortages. Mathematical Problems in Engineering, 1-24. doi:10.1155/2009/679736

Tayal, S., Singh, S.R., \& Sharma, R. (2014). An inventory model for deteriorating items with seasonal products and an option of an alternative market. Uncertain Supply Chain Management, 3(1), 69-86.

Taylor, S.G., \& Bradley, C.E. (1985). Optimal ordering strategies for announced price increases. Operations Research, 33(2), 312-325.

Tersine, R.J. (1996). Economic replenishment strategies for announced price increases. European Journal of Operational Research, 92, 266-280.

Tripathi, R.P., \& Tomar, S.S. (2015). Optimal order policy for deteriorating items with time-dependent demand in response to temporary price discount linked to order quantity. International Journal of Mathematical Analysis, 23(9), 1095 - 1109.

Wee, H.M., \& Law, S.T. (1999). Economic production lot size for deteriorating items taking account of the time-value of money. Computers and Operations Research, 26(6), 545-558.

Wee, H.M., \& Law, S.T. (2001). Replenishment and pricing policy for deteriorating items taking into account the time-value of money. International Journal of Production Economics, 71(1-3), 213-220.

Yang, H.L. (2006). Two-warehouse partial backlogging inventory models for deteriorating items under inflation. International Journal of Production Economics, 103(1), 362-370.

Yang, H.L. (2011). A partial backlogging production-inventory lot-size model for deteriorating items with time-varying production and demand rate over a finite time horizon. International Journal of Systems Science, 42(8), 1397-1407.

Appendix A: Concavity of gain functions

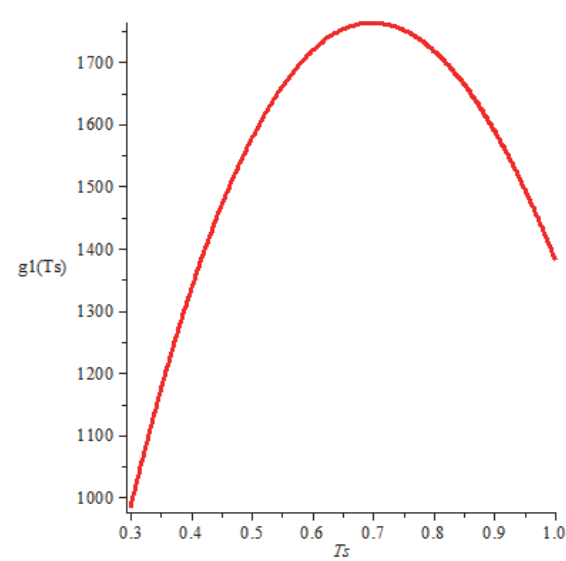

Fig. 3. Concavity of total cost saving $g_{1}\left(T_{s}\right)$

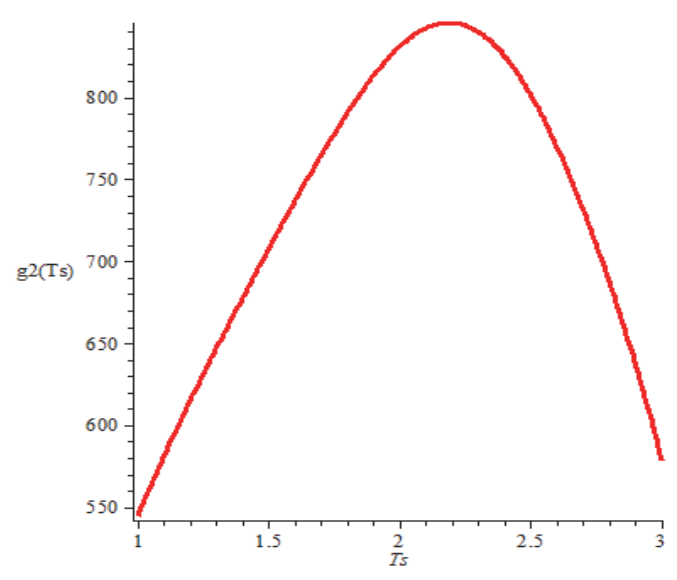

Fig. 4. Concavity of total cost saving $g_{2}\left(T_{s}\right)$ 